\title{
Economia de Comunhão: Responsabilidade Social, Ideología e Representações Sociais
}

\author{
Communion Economy: \\ Social Responsibility, \\ Ideology and Social Representations
}

Economia de Comunion:

Responsabilidad Social, Ideologia y Representaciones Sociales

Maria Luisa Carvalho

Universidade Tecnológica

Federal do Paraná

Pedrinho Guareschi

Pontifícia Universidade

Católica do Rio Grande do Sul
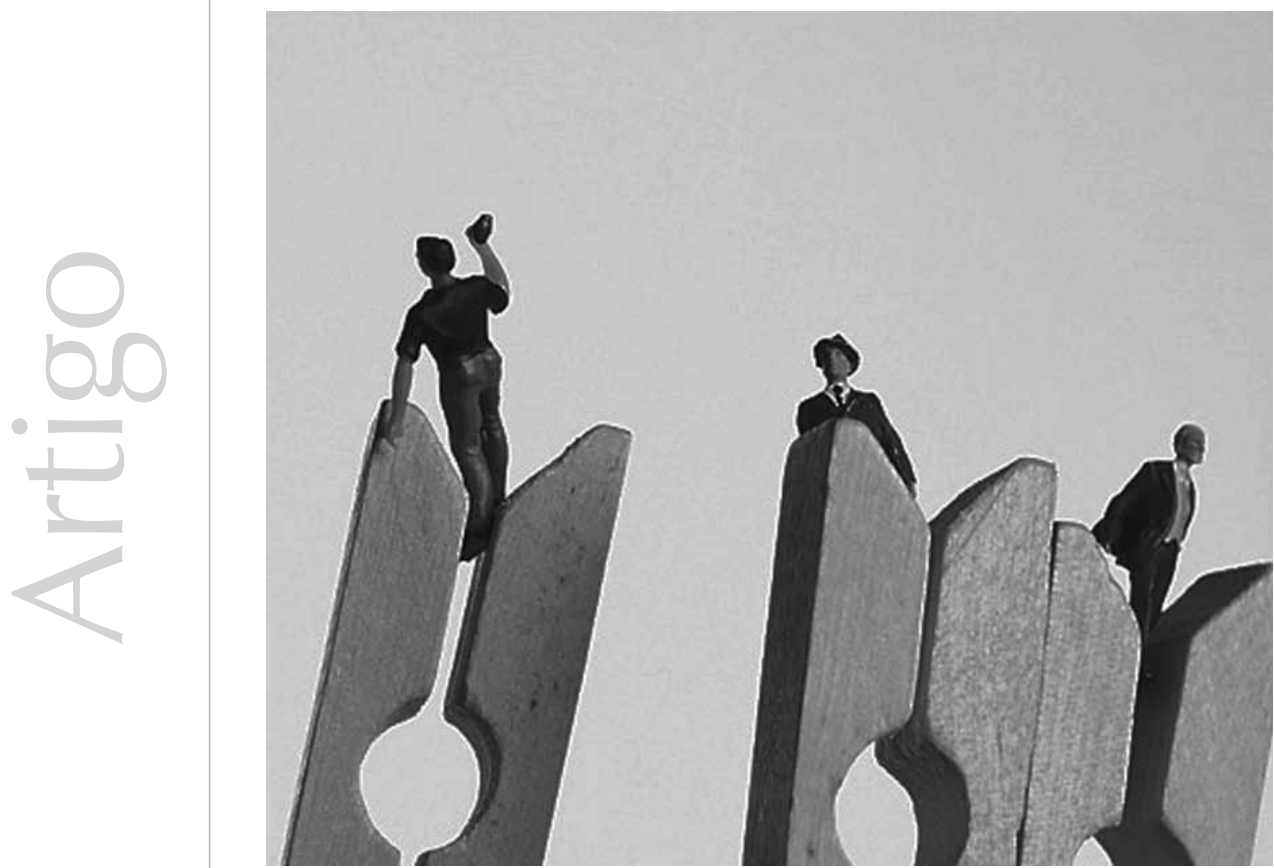
Resumo: $\mathrm{O}$ artigo analisa um caso particular de responsabilidade social - a Economia de Comunhão (EdC) - buscando identificar as representações sociais (Moscovici, 2003) que a constituem e se as mesmas possuem ou não um caráter ideológico (Thompson, 1995). Os dados foram coletados através de visitas a empresas, participação em congressos, pesquisas documental e bibliográfica e a análise realizada a partir da hermenêutica da profundidade (Thompson, 1995). Os resultados indicaram que, através de representações de origem religiosa (lucro como benção divina), de outras já sedimentadas pelo capitalismo (ex. lucro como fruto da competência empresarial) e de representações emergentes (ex. empresário como modelo de ética e competência) a EdC cumpre, ideologicamente, a função de legitimar as mudanças nas relações de trabalho requeridas pelos modelos flexíveis de gestão e suprimir as contradições e conflitos sociais à medida que apresenta o empresário como o grande pai, capaz de oferecer sustento, proteção e afeto a pobres e trabalhadores.

Palavras-chave: Economia de Comunhão. Responsabilidade social. Representações sociais. Ideologia.

Abstract: The article analyzes a peculiar case of social responsibility - the economy of communion (EdC) trying to identify the social representations (Moscovici, 2003) that constitute it and whether they possess or not an ideological character (Thompson, 1995). The data were collected through visits to companies, participation in congresses, documental and bibliographical research and the analysis that was accomplished based on the depth hermeneutics (Thompson, 1995). The results indicated that, through representations of religious origin (profit as divine blessing), through other values accepted by capitalism (profit as a result of business competence) and of emerging representations (the entrepreneur as a model of ethics and competence), EdC accomplishes, ideologically, the function of legitimating the changes in the work relationships requested by the flexible models of administration and of suppressing the contradictions and social conflicts in a way that presents the entrepreneur as the great father, capable of offering sustenance, protection and affection to the poor and to the workers.

Keywords: Economy of communion. Social responsibility. Social representations. Ideology.

Resumen: El artículo analiza un caso particular de responsabilidad social - la economía de comunión (EdC) - buscando identificar las representaciones sociales (Moscovici, 2003) que la constituyen y si las mismas poseen o no un carácter ideológico (Thompson, 1995). Los datos fueron colectados a través de visitas a empresas, participación en congresos, pesquisas documental y bibliográfica y el análisis realizado desde la hermenéutica de la profundidad (Thompson, 1995). Los resultados indicaron que, a través de representaciones de origen religioso (beneficio como bendición divina), de otras ya sedimentadas por el capitalismo (ej. beneficio como fruto de la capacidad empresarial) y de representaciones emergentes (ej. empresario como modelo de ética y capacidad) la EdC cumple, ideológicamente, la función de legitimar los cambios en las relaciones de trabajo requeridas por los modelos flexibles de gestión y suprimir las contradicciones y conflictos sociales a medida que presenta el empresario como el gran padre, capaz de ofrecer sostén, protección y afecto a pobres y trabajadores.

Palabras clave: Economía de comunión. Responsabilidad Social Representaciones sociales. Ideología.

Desde o final do século XX e início do século $\mathrm{XXI}$, as relações econômicas, principalmente as relações de trabalho, vêm passando por uma série de transformações, mas que não chegam a suplantar o modo de produção capitalista, que continua central. Para Harvey (1996), o que vivenciamos é uma nova fase, denominada capitalismo de acumulação flexível, que é caracterizada pela especulação financeira, pelo emprego de tecnologias que reduzem os postos de trabalho e requerem um trabalhador polivalente, pela substituição do modelo taylorista-fordista pelo modelo toyotista (produção enxuta) e pela terceirização e mercantilização do saber, dentre outras.

O neoliberalismo constitui o modelo de ajuste da economia proposto nessa nova fase, e desdobra-se em três frentes articuladas: a reestruturação produtiva, a (contra) reforma do Estado e a transformação da sociedade civil em Terceiro Setor, vinculada também à responsabilidade social empresarial (Montaño, 2003; Palharini, 1995). Embora considerando a articulação entre as três frentes, este 
A reestruturação produtiva

caracteriza-se pela implementação de modelos flexíveis de gestão, nos quais a mais-valia não se baseia apenas na quantidade de trabalho, mas a ela são somados outros elementos, como a gestão do capital do conhecimento, a participação, o comprometimento, a disciplina coletiva e o aprisionamento da subjetividade, que adquirem uma importância determinante na produtividade do capital

(Guattari, 1977). artigo buscará discutir particularmente as questões da reestruturação produtiva e da responsabilidade social.

A reestruturação produtiva caracteriza-se pela implementação de modelos flexíveis de gestão, nos quais a mais-valia não se baseia apenas na quantidade de trabalho, mas a ela são somados outros elementos, como a gestão do capital do conhecimento, a participação, o comprometimento, a disciplina coletiva e o aprisionamento da subjetividade, que adquirem uma importância determinante na produtividade do capital (Guattari, 1977). A contradição funcional se faz presente à medida que, para obter a adesão dos trabalhadores, são desenvolvidas sofisticadas formas de gestão de pessoas (participação nos lucros, endomarketing) e, ao mesmo tempo, observa-se um aumento da pressão sobre os trabalhadores, do assédio moral e da descartabilidade dos mesmos.

Já o fenômeno da responsabilidade social difere das formas anteriores de filantropia empresarial por buscar se desvencilhar das práticas caritativas tradicionais, promovendo sua "profissionalização" e transformando a ação social em uma estratégia empresarial. Nessa perspectiva, o empresário passa a figurar como um modelo de sucesso e ética que, com sua competência, é capaz de, ao mesmo tempo, gerar resultados financeiros para as organizações e solucionar os problemas sociais, como a pobreza.

Nesse cenário, para legitimar e garantir a reprodução das relações básicas de produção capitalistas, novas construções sociais, ideológicas, políticas e religiosas, dentre outras, estão surgindo. Essas construções sociais são denominadas por Moscovici (2003) de representações sociais. As representações sociais não são, como se poderia ingenuamente pensar, cópias ou reproduções de determinada realidade física ou social. As representações sociais são construções simbólicas que têm, contudo, um status ontológico em si mesmas; são, como diz Moscovici (2003), "entidades sociais em si mesmas" (p. 38).
A importância de investigar a origem de uma representação social se deve ao fato de que, quando isso não ocorre, a mesma acaba se "fossilizando", tornandose algo dado, permanente, legitimado, reificado, naturalizado. Realizar o estudo das propriedades, das origens e do impacto das representações sociais é tarefa primordial da Psicologia social (Moscovici, 2003).

O presente artigo busca discutir uma representação social em especial - a Economia de Comunhão - que responde a interesses específicos de determinados grupos e de determinado contexto histórico: as mudanças nas relações de trabalho na era da informação e como esse modo de produção capitalista necessita se readaptar aos novos tempos. Evidentemente, as representações sociais, essas construções mentais e sociais, carregam em si uma ideologia, que será aqui analisada e discutida.

Proposta em 1991, no Brasil, pela italiana Chiara Lubich, fundadora e presidente do Movimento dos Focolares (MF), a Economia de Comunhão (EdC) apresenta-se como uma proposta para solucionar o problema da pobreza através da criação de empresas que sigam princípios éticos, efetuem doações financeiras aos pobres e difundam uma cultura de partilha dos bens.

A análise do projeto Economia de Comunhão aqui apresentada parte do referencial das teorias das representações sociais (Moscovici, 2003) e da ideologia (Thompson, 1995), buscando identificar que representações sociais constituem e são constituídas na EdC, particularmente as relacionadas ao empresariado, à empresa, ao trabalhador, ao trabalho, à pobreza e à riqueza, bem como busca analisar se as mesmas possuem ou não um caráter ideológico, ou seja, se são utilizadas para estabelecer e sustentar relações de dominação.

O artigo encontra-se assim estruturado: a seguir são descritos os procedimentos metodológicos do estudo, e depois são apresentados e discutidos os resultados do mesmo. 


\section{Considerações metodológicas}

A presente pesquisa consiste em um estudo de caso, que buscou compreender o fenômeno da espiritualidade nas organizações a partir das empresas de Economia de Comunhão. Os dados foram coletados a partir das participações nos congressos nacionais de $E d C$, pesquisa bibliográfica e a fontes documentais diversas (periódicos sobre EdC, cadernos de formação dos empresários, arquivos com dados sobre as empresas cadastradas no Brasil) e entrevistas com empresários e trabalhadores realizadas durante as visitas a três empresas de EdC.

A escolha das empresas se deu segundo critérios de acessibilidade (as empresas estavam localizadas nas Regiões Sul e Sudeste do Brasil). Foram pesquisadas: uma confecção situada na Grande São Paulo (Da Moda Confecções), com 10 trabalhadores; uma metalúrgica (Meta Metalúrgica) localizada em Santa Catarina, com 50 trabalhadores, e uma distribuidora de medicamentos (Saúde Medicamentos), com sede no Paraná, com 78 trabalhadores na época da pesquisa. Foram realizadas entrevistas semi-estruturadas, individuais, com 7 empresários e 20 trabalhadores. Por questões éticas, foram alterados os nomes das empresas e dos sujeitos da pesquisa.

Depois de transcritas as entrevistas e selecionados os dados obtidos através das outras fontes, procedeu-se à análise dos mesmos através da hermenêutica da profundidade (Thompson, 1995), que incluiu a fase de análise sociohistórica, através do qual o fenômeno estudado foi contextualizado no cenário da reestruturação produtiva e do sistema capitalista; a análise formal, no caso, realizada através da análise de conteúdo (Bardin, 2000), e a interpretação/re-interpretação pautada na ideologia (Thompson, 1995), segundo a qual ideologia consiste no modo como as formas simbólicas são empregadas para gerar e manter relações de dominação. Destaca-se, por fim, que foi feita a validação comunicativa
(Gaskell \& Bauer, 2002) do estudo através da apresentação das análises aos membros de um grupo virtual de discussão sobre a EdC.

A seguir são apresentados os resultados e a análise dos dados realizada a partir do referencial da teoria das representações sociais (Moscovici, 2003) e da ideologia (Thompson, 1995).

\section{Compreendendo a Economia de Comunhão como uma representação social}

As origens da Economia de Comunhão

Conforme foi apontado na introdução deste capítulo, a Economia de Comunhão está vinculada ao Movimento dos Focolares (MF). Trata-se de um movimento católico surgido em 1943, durante a Segunda Guerra Mundial, em Trento, na Itália, tendo por fundadora e atual presidente Chiara Lubich, e que tem por objetivo promover a fraternidade entre os povos. Atualmente, está presente em 182 países, tendo como participantes pessoas de diferentes faixas etárias (de crianças a idosos), diferentes raças, línguas e credos, envolvendo outras denominações cristãs, não-cristãos e pessoas sem uma referência religiosa. No Brasil, o movimento iniciou sua atuação em 1958 (Araújo, 1998; Lubich, 2002).

Segundo relatos, durante uma viagem ao Brasil, em maio de 1991, Chiara Lubich teria se sensibilizado com a difícil situação econômica e a enorme desigualdade social do país, sendo também de seu conhecimento que pessoas pertencentes ao Movimento do Focolares viviam em condição de pobreza, e teria lançado o projeto de Economia de Comunhão, propondo a criação de empresas que doariam parte dos lucros para os pobres cadastrados pelo Movimento dos Focolares e para a difusão de uma cultura da partilha, através de apoio à divulgação do Movimento dos Focolares e da Economia de Comunhão. Atualmente, existem cerca de 850 empresas de EdC no mundo, sendo 80 localizadas no Brasil (Movimento dos Focolares, n.d.). 
Abaixo tem-se um mapa geral com as características centrais, as dimensões dos valores, das concepções de ser humano e de sociedade que compõem a EdC, que serão discutidas a seguir.

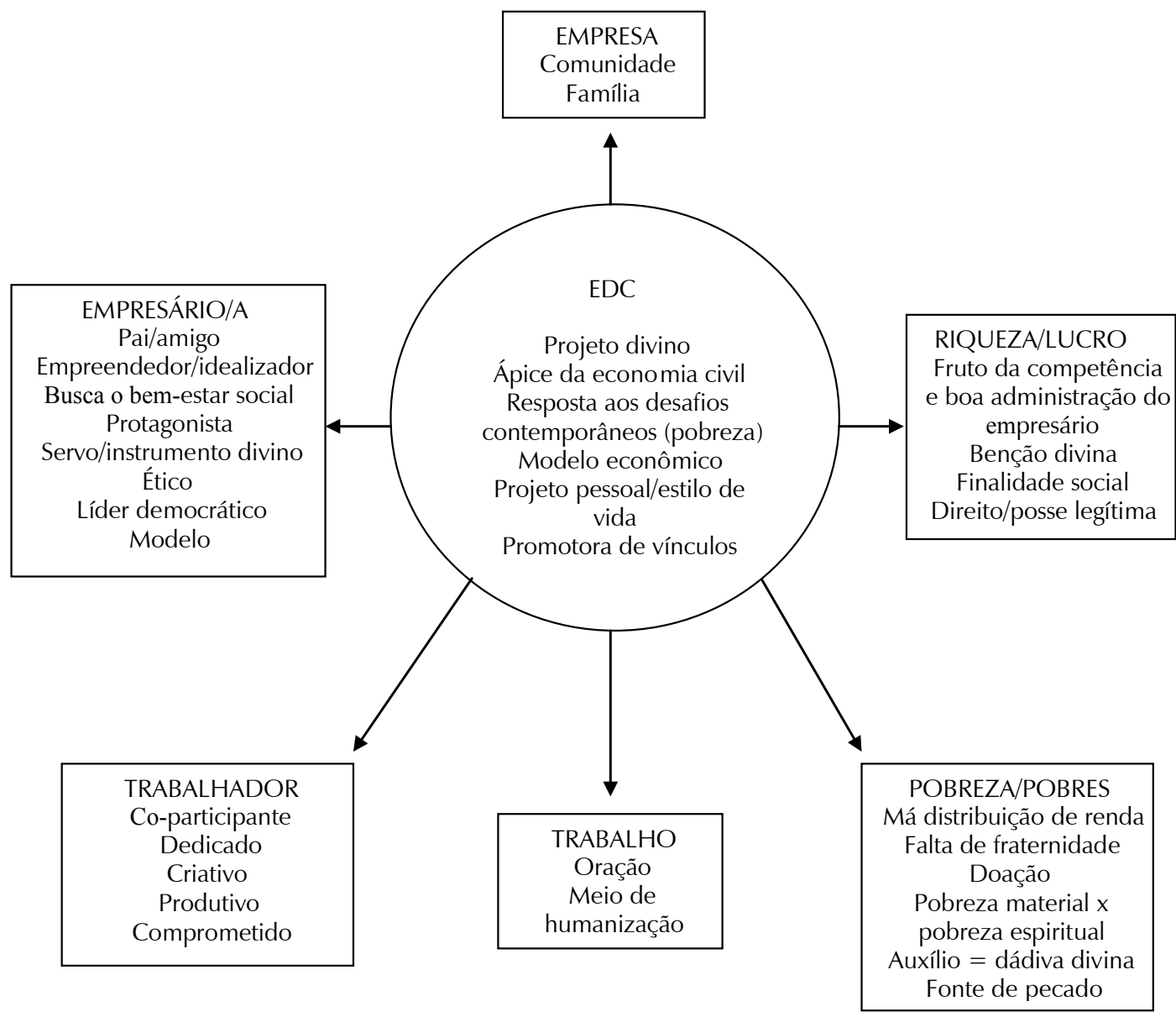

Figura 1: Mapa das dimensões da Economia de Comunhão.

Fonte: Elaborado pela autora

\section{A Economia de Comunhão: uma obra de Deus}

A EdC é apresentada por seus idealizadores e atores como um projeto divino. Para Lubich (2004), a EdC tem "raízes no Céu", afirmação que é aceita, introjetada e repetida pelos membros do Movimento dos Focolares, como é o caso de Ferrucci (1998b), que afirma que "EdC visa atrair a intervenção divina para o mundo dos negócios". Deus é considerado como o "sócio invisível" que se manifesta na empresa através da Providência Divina: "Narrar a história da EdC é como narrar a história de uma obra de Deus" (Paulo, empresário).

As afirmações acima parecem uma tentativa de romper a dicotomia sagrado x profano e de conferir sacralidade ao trabalho e aos negócios. Assim, ao administrar sua empresa a partir dos princípios da EdC, o empresário acredita fazer não apenas uma ação humana mas também colaborar com a ação divina, o que confere um sentido de realização e transcendência à sua prática de gestor. Entretanto, para além das crenças dos membros do MF, a ênfase dada à "sacralidade" do projeto, em detrimento de sua historicidade, pode ser vista como um modo ideológico de legitimação do mesmo, de lhe conferir crédito e apoio a partir de um fundamento religioso. Esse aspecto 
pode ser percebido durante a pesquisa, pois foi identificada uma idealização da EdC que dificulta a possibilidade de crítica, o apontamento de qualquer deficiência, contradição e limitação da mesma por parte de seus empresários e teóricos.

Segundo Ferrucci (1998a) e Mulatero (2001), a EdC busca ser uma resposta pacífica aos desafios contemporâneos, especialmente o combate à pobreza, através da promoção da cultura da partilha pautada no uso moderado e na partilha dos bens (materiais e não materiais). Os autores afirmam ainda que as empresas de $\mathrm{EdC}$ promovem a distribuição da riqueza através de doações monetárias, criação de empregos, investimento em projetos de expansão, compartilhamento de experiências e patentes entre as empresas que participam do projeto e financiamento para criação de novas empresas de EdC.

Nessa tentativa de responder aos desafios contemporâneos, Gui e Bruni (2001) afirmam que a $E d C$ não entra em conflito com o capitalismo, sendo que a própria distribuição dos lucros não é tida como algo revolucionário e novo. Para eles, o radicalismo da proposta encontra-se nos aspectos antropológico e cultural, ao propor um modelo econômico pautado na comunhão, amor, gratuidade e reciprocidade. Tais afirmações geram certa perplexidade: não é contraditório afirmar que uma proposta que introduz tais conceitos não entre em conflito com um modelo econômico pautado na acumulação, competição, instrumentalidade e individualismo, como é o capitalismo?

Essas contradições parecem não ser explicitadas pela EdC devido ao fato de sua perspectiva de mudança social ser pautada em uma visão de que é a mudança interior do sujeito que promove mudanças na sociedade. Assim, segundo Bruni (2005), a EdC é um novo modo de viver, uma "vocação interior". É a vivência de valores como o amor ao próximo, a gratuidade, a comunhão e a reciprocidade que fazem com que uma empresa seja considerada como de EdC. Nesse sentido, a mesma pode ser compreendida como um projeto pessoal, um estilo de vida que busca romper a dicotomia de que há uma ética referente à esfera econômica e outra às demais esferas da vida. Tal aspecto foi ressaltado pelos empresários pesquisados, que afirmaram que a EdC indicou-lhes o caminho para praticar seus valores e crenças religiosas no âmbito dos negócios, no qual predomina a competição. A associação entre a $\mathrm{EdC}$ e um estilo de vida ficou explícito nas visitas às empresas bem como nos depoimentos dos empresários nos congressos nacionais de $\mathrm{EdC}$, nos quais não foram identificadas mudanças significativas no que se refere aos aspectos estruturais e na gestão. O foco encontra-se no relacionamento próximo e amistoso estabelecido com os trabalhadores e na busca pela vivência da espiritualidade do MF no ambiente de trabalho, incluindo a adoção de práticas religiosas como orações.

Nesse sentido, a EdC aproxima-se, ao contrário do que o termo comunhão sugere, de uma cosmovisão individualista, segundo a qual a sociedade é composta pela soma de seus indivíduos. O aspecto "coletivo" da EdC estaria no fato de que as pessoas a ela vinculadas (empresários, pobres e alguns trabalhadores) fazem parte do MF e periodicamente se reúnem para a troca de experiências. As ações (doações dos lucros e, no caso dos pobres, busca de um emprego e superação do estado de carência material), entretanto, são individuais e pontuais.

A EdC é apontada ainda como um modo de produzir riqueza que tem por especificidade a criação e a manutenção do vínculo interpessoal por meio da demonstração concreta de que é possível participar do mercado, ser competitivo, porém sem o condicionamento derivante de uma estrutura motivacional que tem o lucro como única finalidade da atividade econômica (Gui, 2002). De fato, como comentado anteriormente, ao longo das visitas às empresas, o que mais chamou a atenção foi a ênfase no estabelecimento de relacionamentos informais, primários, entre empresários e trabalhadores. 
Embora apontem que, ao contrário do que acontece nas ações tradicionais de responsabilidade social, a ação dos empresários da EdC não tem motivações instrumentais, mas religiosas, costuma-se destacar, na fala dos empresários e nas palestras dos congressos, que, indiretamente, o modelo de gestão adotado na $\mathrm{EdC}$ acaba por gerar vantagem competitiva:

Eu acho, pelo contrário, nestes dez anos que eu estou participando, doze, treze, eu não me lembro quanto, eu acho que a Economia de Comunhão tem se mostrado até mesmo uma vantagem competitiva, porque o mercado busca empresas e propostas sérias. (Carlos, empresário)

Feita essa apresentação geral da Economia de Comunhão, passamos agora a demonstrar como a mesma concebe a questão da riqueza e do lucro.

A riqueza e o lucro na perspectiva da Economia de Comunhão

No próprio discurso de anúncio do projeto de EdC, Chiara Lubich afirma que, para que dêem lucro, as empresas devem ser administradas por pessoas competentes. Assim, a riqueza/lucro são vistos como frutos da competência do empresário. Os trabalhadores e os empresários entrevistados também apresentaram essa visão, afirmando que o lucro é um produto da qualidade, da produtividade, da redução de custos, é uma operação matemática: "O lucro da empresa? Eu acho que vem da questão da administração, de saber administrar, de saber ver o valor da matéria-prima, de quanto tá gastando, e saber vender, né?" (Jonas, auxiliar de produção).

O empresário que adere à EdC ainda pode contar com o auxílio divino na gestão de seus negócios, sendo que a riqueza e o lucro gerados pelas empresas de EdC são vistos também como sinal de bênção divina. Lubich (2004, p. 45) afirma que, se o empresário vive os princípios da EdC, alcançará prosperidade, pois Deus atuará na empresa: "É a caixa celeste que se abre no momento oportuno".
Tal concepção é recorrente nos depoimentos apresentados nos congressos de $\mathrm{EdC}$ e nas entrevistas dos empresários, que afirmam que, quando seguem os princípios éticos da EdC, os negócios prosperam. Essa concepção também é percebida no depoimento abaixo de um dos pobres que recebe auxílio das empresas: "Peço a Deus que multiplique os lucros das empresas, de modo que eles possam chegar a muitas pessoas" (assistido do Uruguai).

Para a $\mathrm{EdC}$, a busca pelo lucro não deve ser vista como um fim em si mesmo ou tendo por objetivo apenas o enriquecimento do empresário, mas como uma finalidade social, que deve ser gerado para depois ser distribuído pela sociedade. Atualmente, a sociedade é representada pelo Movimento dos Focolares, uma vez que parte dos lucros é destinada para sua manutenção (parte destinada à difusão da cultura da partilha) bem como para auxiliar seus membros carentes (doação aos pobres). Quanto aos demais integrantes da sociedade, são considerados distribuição da riqueza o pagamento de impostos, a geração de emprego e os salários, o que não foge das definições tradicionais da finalidade social das empresas (Sorgi, 1998a).

O lucro também não deve ser alcançado por meios ilícitos. Assim, dentre os preceitos da EdC, estão a rejeição de práticas como a concorrência desleal, o pagamento de subornos e a sonegação de impostos. Os dados coletados citam diversas situações em que os empresários deixaram de realizar negócios devido a sugestões de propina ou de sonegação de impostos.

Os dados apresentam uma visão segundo a qual o processo de produção, expropriação e distribuição de riqueza são concebidos como distintos, ou seja, como se o modo de a sociedade se organizar para produzir riqueza, em particular no capitalismo, não estivesse associado à produção também da pobreza.

Uma vez que não questiona a empresa capitalista, mas insere-se nela, o projeto de 
EdC considera que o lucro é posse legítima do empresário, que detém os meios de produção. Assim, a doação que ele faz é fruto de uma renúncia, e não questão de justiça social:

É um fato comovente! Eles poderiam colocar no bolso os lucros obtidos, comprar um casaco de pele para a esposa, novos presentes para os filhos, um carro para o filho... mas não o fazem, pois vivem um grande ideal e são coerentes. ...Que Deus os abençoe e lhes dê o cêntuplo já aqui nesta vida, e depois a vida eterna. (Lubich, 2004, pp. 44-45)

Nos dados acima citados, pode-se perceber elementos que não são exclusivos da EdC, como a representação do lucro e da prosperidade como sinal de bênção divina, mais divulgada, porém, entre os cristãos vinculados ao protestantismo do que entre os católicos. Percebe-se aqui a reificação como modo de operação ideológica. Por meio da estratégia de naturalização, a produção de riqueza é desvinculada de seu contexto econômico e histórico (o modo de produção capitalista) e vinculado a características pessoais ou a fenômenos espirituais. Reforçase a questão da meritocracia, tão cara ao capitalismo, segundo o qual as mazelas ou benefícios da vida são fruto de méritos pessoais.

Associadas a explicações sobre a origem e a finalidade da riqueza, existem as percepções acerca da pobreza, discutidas a seguir.

\section{A pobreza e os pobres}

Identificaram-se, nos dados coletados, representações da pobreza como fruto da má distribuição de renda, porém, sem que houvesse maior aprofundamento a respeito de como ocorre esse processo, que parece mais um "jargão" do que uma compreensão da realidade: "A origem da pobreza? É a má distribuição de renda" (Nelson, auxiliar de produção).
Explicações de cunho religioso também estão presentes, sendo a pobreza também apresentada como decorrente da falta de fraternidade, do egoísmo, ou seja, tem sua origem nos indivíduos. Para superá-la, é necessário viver a fraternidade e seguir princípios religiosos: "Se a gente vivesse a fraternidade, todo mundo, então não existiria pobreza" (Neide, empresária). “...O principal (motivo da existência da pobreza) é que a pessoa não tem Deus. ...Eu acho que é um pouco esse egoísmo..." (Pedro, auxiliar de escritório).

Para os idealizadores da EdC, os pobres que recebem o auxílio financeiro não são meros beneficiários, mas participam da EdC à medida que "doam sua necessidade" e a ela renunciam em favor de outros (Lubich, 2004). Tais afirmações são incorporadas e repetidas sem reflexão, conforme apontam as falas abaixo:

\footnotetext{
E o que eu aprendi também é que, quando você doa, o outro já doou primeiro. Quando você dá uma esmola numa sinaleira ou pra alguém, você deu por quê, aquela esmola? Porque alguém já pediu. Não é porque você deu primeiro. O outro doou primeiro a necessidade dele, para depois você fazer a sua doação. (Roberto, empresário)

Antes achava que para partilhar fosse necessário ter dinheiro para dar, agora aprendi que posso partilhar a minha pobreza e estou feliz, porque sinto que não recebi apenas uma ajuda econômica, mas também uma alegria extra, uma nova paz e tranqüilidade. (assistido da Argentina)
}

Os dados acima citados indicam que a representação da pobreza presente na Economia de Comunhão é desprovida da dimensão social e abordada apenas do prisma individual e religioso. A pobreza é ainda apresentada sob uma perspectiva positiva, o que caracteriza o modo de operação ideológico da dissimulação, expresso na estratégia de eufemização (Thompson, 1995). O não ter, a pobreza, torna-se "ter", "um dom a ser ofertado", o que remete ainda a 
atribuí-la ao sujeito: a carência não é fruto de um processo social, mas é como se fosse intrínseca ao sujeito, algo que lhe pertence; não é fruto de um processo no qual algo lhe foi expropriado, mas algo a ser doado.

Além disso, a "participação" dos pobres é restrita a solicitar o auxílio e encontrar, por meios próprios, formas de superar sua situação de carência para renunciar ao auxílio em favor dos demais, ou seja, cabeIhes resignarem-se à sua condição de objeto de ação alheia, não podendo ou não tendo outra contribuição ao projeto de EdC. Mesmo quando se atribui uma posição supostamente ativa, de busca de superação de pobreza, essa remete a ações particulares, individuais, o que reforça a responsabilidade do indivíduo por sua situação.

Segundo seus teóricos, embora vise combater a pobreza material, a EdC não foca apenas nessa. Para Bruni $(2004$, p. 7), “...a cultura da partilha e da comunhão, que nos torna todos pobres (como diz o Evangelho), e, pela partilha que atrai o cêntuplo, nos torna todos ricos". Nesse sentido, considera que qualquer necessidade humana não satisfeita é uma forma de pobreza, e qualquer necessidade humana satisfeita é uma forma de riqueza. Assim, o empresário parece sentir-se confortado por viver a "pobreza evangélica", porque doa parte do seu lucro, sem o inconveniente de ter que sentir na pele as mazelas da pobreza material. Já o pobre pode sentir-se rico espiritualmente, à medida que "doa sua necessidade" e também partilha o que recebe com os demais. Tais afirmações podem ser percebidas na seguinte fala de um empresário: "Será que ser rico é ter muito dinheiro? Outro dia ouvi uma expressão assim...: 'eu descobri que eu sou muito pobre, eu só tenho o dinheiro'. Não é profundo?" (Roberto, empresário).

Novamente, tem-se o emprego da estratégia ideológica de eufemização, que confere conotações positivas à pobreza, e de deslocamento, que atribui uma visão negativa à riqueza.
O auxilio oferecido aos pobres e que thes permite atender necessidades básicas (saúde, moradia, educação, alimentação) não é vinculado à questão da cidadania, aos direitos elementares do ser humano, mas apresentado como uma dádiva, não meramente humana, mas igualmente divina, um sinal do amor de Deus para com eles:

Sempre fui muito independente e queria ganhar o suficiente para viver. De repente, porém, precisei de ajuda para enfrentar uma crise econômica imprevista. Era difícil depender de outras pessoas, mas aprendi a ser humilde, com dignidade. Não me envergonho mais, porque entendi que a soma recebida é expressão do amor de Deus por mim. (assistido de Santo Domingo)

Se não receber (a ajuda), ele nem vai ficar zangado, porque ele vive esse espírito de pobreza, vive essa ajuda recíproca também, esse amar-se uns aos outros. (Augusta, empresária)

Os depoimentos dos pobres publicados no periódico Notícias da $E d C$ são repletos de frases que expressam gratidão e humildade. Destaca-se que a indignação pela condição de carência é apresentada como fruto de orgulho que deve ser combatido, como indica o depoimento do assistido de Santo Domingo. Resta aos pobres resignar-se ao papel que a EdC Ihes confere: pedir auxílio, recebêlo, usá-lo comedidamente e buscar o mais prontamente possível meios de subsistência para que possa renunciar à ajuda. Em nenhum momento, teóricos, empresários, pobres e trabalhadores remetem à questão dos direitos fundamentais do cidadão e de conferir aos pobres o papel de sujeito de sua história.

Continuando a perspectiva religiosa, segundo os idealizadores da EdC, a pobreza deve ser combatida porque induz o pobre a pecar. A afirmação gera questionamento: a que tipos de pecado estariam se referindo? À "preguiça", ao "ócio" impostos pelo desemprego? Ao furto para matar a fome? Tal questão não fica clara. Novamente, não se considera a questão da injustiça social nem 
se considera como pecadores aqueles que produzem a miséria: "a miséria", diz São Basílio, "induz ao pecado. Nós não podemos querer o pecado. Portanto, não devemos querer a miséria" (Stefano Zamagni, teórico da EdC, em entrevista a Gui, 2002b, p. 10).

A postura passiva atribuída aos pobres, o direito apresentado como dádiva, a responsabilização do sujeito por sua condição dificulta a mobilização e a ação coletiva dos excluídos, reduzindo-os a objeto da ação alheia. O auxílio recebido gera conforto e sensação de estar protegido, porém, ao invés de promover o empoderamento, a autonomia gera sentimentos de gratidão, submissão e passividade. Assim, a EdC age como uma forma de controle social.

Ainda focadas na questão do modo como a sociedade se organiza para produzir, existem as percepções referentes ao trabalho, que serão discutidas a seguir.

Para Sorgi

(1998b), Chiara propõe uma unificação da proposta beneditina "reza e trabalha", apresentando 0 trabalho como uma forma de oração, como um modo de o ser humano participar da criação e redenção

divinas. Assim, 0 trabalho e seus instrumentos são sacralizados.
O trabalho e o trabalhador

Para Sorgi (1998b), Chiara propõe uma unificação da proposta beneditina "reza e trabalha", apresentando o trabalho como uma forma de oração, como um modo de o ser humano participar da criação e redenção divinas. Assim, o trabalho e seus instrumentos são sacralizados. Além disso, o trabalho é considerado um meio de humanização, fonte de realização pessoal e deve ser libertado de toda instrumentalização alienante e não deve dominar todas as esferas da vida. Entretanto, nas empresas visitadas, principalmente na Meta e na Da Moda, não se observou qualquer mudança na organização taylorista de produção.

Assim, como os pobres, os trabalhadores também são considerados co-participantes. Entretanto, tal "participação" é tão limitada quanto à dos assistidos. Durante a pesquisa, quando indagados sobre a $\mathrm{EdC}$, percebeuse que os trabalhadores tinham uma idéia vaga e, por vezes, nula a seu respeito. Os empresários justificavam tal fato alegando que não fazem "propaganda da $\mathrm{EdC}^{\text {" e que os }}$ trabalhadores devem compreendê-la através das ações do empresariado no cotidiano, na empresa.

Embora também se afirme que as empresas de EdC possuem uma gestão participativa, nas empresas pesquisadas, percebeu-se que não há nenhum canal formal e efetivo de participação dos trabalhadores na gestão da empresa, que se limitam a dar sugestões esporádicas e restritas visando à melhoria dos processos. Segundo os dados coletados, a "participação" dos trabalhadores nas empresas de EdC consiste em serem produtivos e comprometidos, realizando um trabalho com qualidade, a fim de que a empresa seja lucrativa e possa realizar a doação aos pobres. Doam, assim, seu trabalho:

Eles se sentem depois protagonistas do próprio projeto, ou mesmo, não do projeto, mas desse espírito, quer dizer, eles se sentem responsáveis. O trabalhador se insere na Economia de Comunhão construindo a Economia de Comunhão todos os dias com o seu trabalho. E vivendo esses valores dentro da empresa no dia a dia, não é? O trabalhador é superimportante e fundamental, senão não existiria a Economia de Comunhão na empresa, porque uma coisa na Economia de Comunhão é dividir o dinheiro. Isso é exclusivamente opção do dono do capital. Uma outra coisa é construir a mola mestra da Economia de Comunhão, que é o testemunho do dia a dia, que são os relacionamentos, e, sem a participação dos funcionários, não se chega a lugar nenhum. (Irene, empresária)

Segundo Sorgi (1998a), o relacionamento que o empresário da EdC estabelece com os trabalhadores faz com que haja maior dedicação ao trabalho, maior mobilidade e reciclagem diante das transformações tecnológicas e mudanças no mundo do trabalho, além da superação dos aspectos alienantes impostos à psique do trabalhador devido a movimentos repetitivos, exploração do sistema e passividade e rompimento da identificação homem-máquina, substituídos pelo trabalho criativo. Porém, conforme já 
apontado, ao menos nas empresas visitadas, não se observou aspectos que pudessem indicar uma superação da divisão de trabalho taylorista e a centralização da autoridade. Assim, as mudanças ocorrem mais em nível simbólico do que da organização do trabalho: é o relacionamento próximo que o empresário estabelece com os trabalhadores que os torna mais dedicados, criativos, produtivos e comprometidos: "...porque a gente até, assim, fica orgulhosa, porque nas nossas notas fiscais, se você observar nas nossas notas, até sai isso: é uma empresa de Economia de Comunhão. ...Todo mundo trabalha assim com a maior boa vontade" (Mariana, supervisora).

O perfil do trabalhador da $\mathrm{EdC}$, embora os empresários e teóricos afirmem seguir uma outra racionalidade, serem guiados por seus princípios religiosos, é o mesmo do "profissional ideal" requisitado pela produção flexível: leal, dedicado, produtivo e criativo. Assim, através do relacionamento próximo e amistoso estabelecido com os trabalhadores, os empresários da EdC alcançam o que as empresas tradicionais buscam incessantemente através de políticas sofisticadas de gestão de pessoas.

Nota-se também, nessas afirmações, que, aos trabalhadores e pobres, cabem as recompensas simbólicas (sentir-se valorizado, reconhecido) enquanto o empresário, além desta, obtém também vantagens financeiras com a adoção da EdC (maior produtividade, redução de custos, etc).

No que diz respeito ao empresário, as características apresentadas correspondem a uma imagem positiva, de alguém que é percebido como exemplo para os demais, como será visto a seguir.

O empresário da Economia de Comunhão: um instrumento divino

Conforme já apontado, o empresário é o protagonista do projeto de $E d C$, cabendo a ele também, através da vivência da espiritualidade do MF no cotidiano da empresa, implantar e divulgar seus princípios: "...eu entendo, entendia e ainda entendo que a Economia de Comunhão é uma opção dos proprietários da empresa. Eles têm o direito de optar ou não, porque, afinal das contas, o dinheiro que vai pra economia é dos proprietários" (Carlos, empresário).

Também é repetido o discurso atualmente em voga que torna o empresário sinônimo de líder democrático, empreendedor e idealizador. Lubich (2004) aponta ainda os empresários da EdC como os principais instrumentos suscitados por Deus para combater o problema da pobreza. O empresário da EdC passa a considerar, assim, superada a dicotomia anteriormente por eles sentida entre ser cristão e buscar o lucro:

Chiara veio com uma proposta que diz o seguinte: "Você deve ser competente, você deve ser dos melhores, você deve gerar lucros, você deve mostrar pro mundo uma nova economia". Isso me realizou muito, porque foi como se ela dissesse: usem todos os seus talentos, faça esses talentos frutificarem, melhorarem, façam o melhor possível e mostrem pro mundo que é possível uma nova economia, mostrem que o modelo que está aí não é o modelo certo. Então, isso veio lá da realização profissional, também como vocação de empreendedor, associada a um projeto, digamos assim, humano, mas com um cunho social fantástico. (Carlos, empresário)

Na fala dos trabalhadores, os empresários são apresentados como pessoas próximas, como pais, amigos que protegem e se preocupam com eles, bem como modelos não apenas no âmbito profissional, mas igualmente na esfera familiar e religiosa: "O cara é um paizão da gente. ...Eu gosto de me sentir desse jeito..., ele preocupado comigo. Sabe como é que é? "(Nelson, auxiliar de produção). "O Carlos e a Irene, eles têm uma relação assim, muito bacana, muito legal, isso me ajudou muito no meu relacionamento interno com o meu esposo" (Ana, supervisora).

Ao apontar o empresário como o protagonista e sob um prisma exclusivamente positivo, a 
EdC corrobora com a transição em curso da representação do empresariado. Se, anteriormente, o mesmo era tido como um vilão social, hoje se observa um processo no sentido oposto. Rostos de empresários estampam jornais e revistas, e são apresentados como modelos de sucesso financeiro, profissional e pessoal. Além disso, ganham status de protagonistas sociais, sob a afirmação de que, com sua competência, são capazes não apenas de gerir bem suas empresas mas também de resolver os problemas sociais. A sociedade parece assim passar da tutela do pai-Estado para a tutela da mãe-empresa, como discutido a seguir.

\section{A empresa-comunidade}

Em sintonia com a comparação do empresário como pai e com a ênfase nos relacionamentos interpessoais, identificou-se uma analogia entre as empresas de EdC e uma comunidade e uma família, ou seja, um lugar que remete ao aconchego, à proteção, à harmonia, no qual seus integrantes estabelecem relacionamentos próximos. Comparar a empresa a uma comunidade implica ainda não restringi-la a um ambiente de trabalho, mas permitir a expressão de outras esferas da vida, como a família e a religião. Nas empresas Meta e Saúde, os familiares são envolvidos em atividades recreativas e festivas da empresa, havendo também rituais religiosos, como orações e encontros sobre a espiritualidade do MF, presentes também na Da Moda Confecções:

Podemos formar, na empresa, comunidades de trabalho que vivam a "arte de amar", valorizando as pessoas pelo que elas são. A esperança e a confiança se restabelecem quando todos sabem que as decisões são tomadas por amor, e não por interesse próprio ou corporativista. E quem acata essas decisões o faz não por obrigação, mas com convicção, entendendo o processo em benefício do todo, ou seja, de cada integrante da empresa, incluindo seu público externo (clientes, fornecedores, comunidade, etc). (Paulo, empresário, palestra no Congresso Nacional de EdC, em 2003)
Eu acho que é próprio deles, deles da diretoria, eu falo do Carlos e a Irene. É aquela grande família, um se preocupa com o outro, faz.. (Gabriela, estagiária)

A força desse imaginário da empresacomunidade sobre os trabalhadores pode ser compreendida à medida que a mesma mobiliza os desejos inconscientes de proteção e segurança de sujeitos que se vêem à deriva em uma sociedade marcada pela competição, pelo individualismo e pela conseqüente fragilidade dos vínculos sociais, o que gera sentimentos de insegurança e solidão.

Para Schirato (2004), atribuir à organização o papel de família é um grande equívoco e no mínimo uma ingenuidade, uma vez que a organização não tem condições de atender a tal demanda. Fazer com que o trabalhador se sinta em família no ambiente de trabalho, tocando-o por apelações afetivas, faz com que se crie um imaginário enganador, que o apresente como um "filho", o que significa ser amado incondicionalmente, o que não corresponde à realidade organizacional.

A relação de proximidade e igualdade apresenta um caráter simbólico e é unilateral nas empresas de $\mathrm{EdC}$, uma vez que é o empresário que se aproxima dos trabalhadores, trabalhando no mesmo espaço físico, cumprimentando a todos diariamente e envolvendo-se com as questões particulares dos mesmos. Constrói-se, assim, uma representação através da qual as diferenças sociais são apenas aparentes, ou seja, há uma supressão das contradições de classe. Cria-se uma percepção na qual há uma perfeita harmonia entre os interesses dos empresários e dos trabalhadores. $\mathrm{O}$ caráter ideológico de tais afirmações se pauta na unificação que visa a construir, em um nível simbólico, uma forma de unidade que interliga os indivíduos em uma unidade coletiva, independentemente das diferenças e divisões que possam separá-los. 
Percebe-se novamente a estratégia de dissimulação, uma vez que as relações de dominação são obscurecidas. Nesse sentido, observa-se que os trabalhadores percebem os empresários como pares, e as diferenças sociais são atenuadas. Não se pode, nem se quer, ser maniqueísta e considerar que a relação entre empresário e trabalhador seja apenas de ódio e conflitos. Ao contrário, considero sua dialética de dependência/ independência, submissão/emancipação e, porque não, a amor e ódio. A forma, entretanto, como é descrita na $\mathrm{EdC}$ suprime qualquer contradição, qualquer aspecto que denote algo de negativo, apontando uma harmonia que é ilusória, como se fosse possível uma total identificação entre os interesses empresariais e os dos trabalhadores.

A seguir, são apresentadas algumas reflexões complementares sobre a $\mathrm{EdC}$ e o contexto no qual ela se insere.

\section{Reflexões finais}

Os resultados indicaram que a $E d C$, enquanto representação social, articula ideologicamente representações de origem religiosa (ex. lucro como benção divina, pobreza como virtude) a outras já sedimentadas no discurso capitalista (ex. lucro como fruto da competência empresarial) bem como a representações emergentes (ex. empresário como modelo de ética e principal protagonista social), reafirmando os princípios neoliberais à medida que legitima suas bases: a reestruturação produtiva, a contra-reforma do Estado e a transformação da sociedade civil em Terceiro Setor.

Nesse novo cenário, mais do que o trabalho braçal, monótono e maçante, a competitividade e geração do lucro passam a ser obtidos através do que Aktouf (2004) denomina exploração da "mais-valia da manipulação", da subjetividade e das energias libidinais, que implica refinar os modos de manipulação dos trabalhadores, promovendo a modificação de seus valores, crenças, representações mentais, símbolos, imagens de si e ideal do ego, dentre outros. Promove-se, assim, uma relação de apropriação simbólica entre o trabalhador e a empresa, sem que seja necessária qualquer alteração no que se refere ao plano materialconcreto e às relações de poder, ou seja, cria-se, apenas no plano simbólico, um imaginário de harmonia organizacional, sem que haja mudanças significativas na maneira de organizar o trabalho, de partilhar o lucro, a autoridade, a propriedade.

Portanto, a Economia de Comunhão constitui uma expressão da reestruturação do capitalismo, na qual a empresa é posta como centro da sociedade, capaz de produzir riqueza e, ao mesmo tempo, de combater a pobreza, bem como é apresentada como a grande família, capaz de oferecer sustento, proteção e afeto aos trabalhadores e pobres. Tais práticas reforçam a passividade social e mantêm as relações de dominação, embora sejam dissimuladas por práticas parternalistas e assistencialistas.

Como alertam Cattani (2003) e Spink (2004), a construção de uma "outra economia", da busca de soluções para a miséria e para a degradação ambiental requer a necessidade de lançar um olhar atento e crítico a fim de distinguir as possibilidades e deficiências dos projetos apresentados bem como de identificar aqueles que, por detrás de "boas intenções", continuam a repetir a lógica capitalista. Sendo assim, se os empresários da EdC pretendem construir uma economia capaz de concretizar a comunhão, faz-se necessário, inicialmente, que sejam capazes de assumir as limitações e as contradições que a mesma possui. 


\section{Maria Luisa Carvalho}

Doutora em Psicologia - PUCRS, professora adjunta da Universidade Tecnológica Federal do Paraná (UTFPR).

\section{Pedrinho Guareschi}

Doutor (PhD) em Psicologia (University of Cambridge/University of Wisconsin at Madison), professora titular da Pontifícia Universidade Católica do Rio Grande do Sul (PUCRS).

\section{Endereço para envio de correspondência:}

Pontifícia Universidade Católica do Rio Grande do Sul, Faculdade de Psicologia AV. Ipiranga, 6681 - prédio 11 sala 803, Partenon. Cep: 90619-900 - Porto Alegre-RS E-mails: mluisacarvalho@pop.com.br / guareschi@pucrs.br

Recebido 30/01/2008; Reformulado 11/08/2008; Aprovado 18/08/2008.

Referências

Araújo, V. (1998). Economia de comunhão e comportamentos sociais. In R. Costa et al., Economia de Comunhão (2a ed., pp. 9-20). Vargem Grande Paulista, SP: Cidade Nova.

Aktouf, O. (2004). Pós-globalização, administração e racionalidade econômica: a síndrome do avestruz. São Paulo: Atlas.

Bardin, L. (2000). Análise de conteúdo. Lisboa: Edições 70.

Bruni, L. (2004). A cultura da proximidade. Economia de Comunhão: uma Nova Cultura, (18), pp. 6-7.

Bruni, L. (2005). Comunhão e as novas palavras em economia. Vargem Grande Paulista, SP: Cidade Nova.

Cattani, A. D. (2003). A outra economia: os conceitos essenciais. In A. D. Cattani (Org.), A outra economia (pp. 9-14). Porto Alegre: Veraz Editores.

Ferrucci, A. (1998a). Considerações sobre a economia de comunhão. In R. Costa et al., Economia de comunhão (2a ed., pp. 69-92). Vargem Grande Paulista, SP: Cidade Nova.

Ferrucci, A. (1998b). Inferno e paraíso. Economia de Comunhão: uma Nova Cultura, (7), p. 2

Gaskell, G., \& Bauer, M. (2002). Para uma prestação de contas pública: além da amostra, da fidedignidade e da validade. In M. Bauer \& G. Gaskell (Orgs.), Pesquisa qualitativa com texto, imagem e som: um manual prático (pp. 470-490). Petrópolis, RJ: Vozes.

Guattari, F. (1977). Revolução molecular: pulsações políticas do desejo. São Paulo: Brasiliense.

Gui, B. (2002a). Evangelho e economia: qual é o espaço da gratuidade? Cadernos do III Encontro de Aprofundamento Cultural e Espiritual da Economia de Comunhão (pp. 7-14). Vargem Grande Paulista, SP. (Mimeografado)

Gui, B. (2002b). Entrevista com Stefano Zamagni. Economia de Comunhão: uma Nova Cultura, (15), pp. 10-11.

Gui, B., \& Bruni, L. (2001). A economia de comunhão em "quatro palavras". Economia de Comunhão: uma Nova Cultura, (13), pp. 6-8
Harvey, D. (1996). A condição pós-moderna. São Paulo: Loyola.

Lubich, C. (2002). A experiência economia de comunhão: da espiritualidade da unidade, uma proposta de agir econômico. In L. Bruni (Org.), Economia de comunhão: uma cultura econômica de várias dimensões (pp. 13-19). Vargem Grande Paulista, SP: Cidade Nova.

Lubich, C. (2004). Economia de comunhão: história e profecia. Vargem Grande Paulista, SP: Cidade Nova.

Montaño, C. (2003). Terceiro setor e questão social: crítica ao padrão emergente de intervenção social (2a ed.). São Paulo: Cortez.

Moscovici, S. (2003). Representações sociais: investigações em psicologia social. Petrópolis, RJ: Vozes.

Movimento dos Focolares. (n.d.). Recuperado em 10 de janeiro de 2008, de http://www.focolares.org.br

Mulatero, C. (2001). Os pobres, "atores" do projeto de EdC. Economia de Comunhão: uma Nova Cultura, (13), p. 12

Palharini, F. de A. (1995). Anotações para uma discussão sobre a filosofia da "qualidade" e suas repercussões na Psicologia. Revista do Departamento de Psicologia - UFFF, 7(2/3), 124-134.

Schirato, M.A. R. (2004). O feitiço das organizações: sistemas imaginários (2a ed.). São Paulo: Atlas.

Sorgi, T. (1998a). A cultura do dar. In R. Costa et al., Economia de comunhão (2a ed., pp. 31-68). Vargem Grande Paulista, SP: Cidade Nova.

Sorgi, T. (1998b). A "santa" economia. Economia de Comunhão: uma Nova Cultura, ano III, (1), pp. 4-5.

Spink, P. (2004). Redes solidárias, autogestão e solidariedade. In N. Guareschi (Org.), Estratégias de invenção do presente: a psicologia social no contemporâneo. Porto Alegre: EDIPUCRS.

Thompson, J. B. (1995). Ideologia e cultura moderna: teoria social crítica na era dos meios de comunicação de massa. Petrópolis, RJ: Vozes. 